\title{
Effect of Fluoxetine and Paroxetine on Intestinal Motility in Presence of Ondansetron in ex-vivo Model
}

Ayesha Afzal ${ }^{1}$, Ammara Khan ${ }^{2}$, Khalida Ajmal $^{1}$, Abeera Sikandar ${ }^{1}$, Saima Rafiqu ${ }^{1}$, Rashida Farooqi ${ }^{1}$, Bushra Tayyaba Khan ${ }^{3}$, Iffat Ara $^{1}$

\section{ABSTRACT}

Objective: To understand the effects of fluoxetine and paroxetine with ondansetron on the intestinal motility of rabbitileum.

Study Design: Observational study.

Place and Duration of Study: The study was conducted from March to April 2018 in a multidisciplinary lab of Army Medical College, Rawalpindi.

Materials and Methods: The contractile effect of intestinal motility was recorded in the power lab. Subjects were twenty four healthy rabbits (Oryctolagus Cuniculus). Semi log dose-response curve was constructed for increasing concentrations of serotonin, ondansetron, fluoxetine, and paroxetine $\left(10^{-9}\right.$ to $\left.10^{-6} \mathrm{M}\right)$ alone and then in the presence of a fixed concentration of ondansetron $\left(10^{-6} \mathrm{M}\right)$ to observe the modulatory role of ondansetron. The serotonin mediated contractions were taken as control.

Results: Ondansetron and serotonin caused an increase in the contractile response of rabbits ileum. A depressive response was observed when the contractions were recorded with increased concentration of fluoxetine and paroxetine in the presence of ondansetron.

Conclusion: Ondansetron when used concomitantly with selective serotonin reuptake inhibitors(SSRIs), abolishes their antidepressant effects by causing a decrease in the intestinal motility of rabbit ileum.

Key Words: Chemotherapy-Induced Nausea and Vomiting, Ondansetron, Power Lab, Serotonin, SSRIS (selective serotonin reuptake inhibitors).

How to cite this: Afzal A, Khan A, Ajmal K, Sikandar A, Rafiqu S, Farooqi R, Khan BT, Ara I. Effect of Fluoxetine and Paroxetine on Intestinal Motility in Presence of Ondansetron in ex-vivo Model. Life and Science. 2020; 1(3): 98-102. doi: http://doi.org/10.37185/LnS.1.1.58

This is an Open Access article distributed under the terms of the Creative Commons Attribution License (http://creativecommons.org/licenses/by/4.0), which permits unrestricted use, distribution, and reproduction in any medium, provided the original work is properly cited.

\section{Introduction}

Major depressive disorder (MDD) is featured by depressed mood most frequently for at least 2 weeks and/or loss of interest or pleasure in most activities. In addition, depression is characterized by

${ }^{1}$ Department of Pharmacology

Wah Medical College

National University of Medical Sciences, Rawalpindi

${ }^{2}$ Department of Pharmacology

Nawaz Sharif Medical College

University of Gujrat, Gujrat

${ }^{3}$ Department of Pharmacology

Army Medical College, Rawalpindi

Correspondence:

Dr. Ayesha Afzal

Associate Professor, Pharmacology

Wah Medical College

National University of Medical Sciences, Rawalpindi

E-mail:dr.ayeshaafzal@hotmail.com

Funding Source: NUST; Conflict of Interest: NIL

Received: Jul 22, 2019; Revised: Apr 20, 2020

Accepted: Jun 23, 2020 disturbances in sleep and appetite and deficits in cognition and energy. Thoughts of guilt, worthlessness, and suicide are common. ${ }^{1}$ An estimated $5.8 \%$ of men and $9.5 \%$ of women experience depressive episodes in their lifetime. The majority (60\%) of suicidal death is due to depressive illness. ${ }^{2}$ Approximately two-thirds of depressed patients respond to the currently available drug treatments including tricyclic antidepressants and selective serotonin reuptake inhibitors (SSRIs), but prognosis of disease has not improved in recent times. Additionally, these drugs have several side effects. Ondansetron is commonly used in treating vomiting due to chemotherapy drugs, postoperative patients, and radiation therapy. The primary site of action of ondansetron is the chemoreceptor trigger zone (CTZ) but also acts on the peripheral serotonergic receptors. It can be given orally or parentrally. Side effects such as headache 
and gastrointestinal upsets are relatively uncommon. CTZ is sensitive to chemical stimuli and is the main site of action of many emetic and antiemetic drugs. ${ }^{3}$ The blood-brain barrier in the neighborhood of the CTZ is relatively permeable, allowing circulating mediators to act directly in this center. The main circulating mediators are acetylcholine, histamine, 5-hydroxytryptamine (5$\mathrm{HT})$, dopamine, and substance P. Serotonin $\left(5-\mathrm{HT}_{3}\right)$ receptors are the only ligand-gated ion channel of the 5-HT receptors family. ${ }^{4}$ They are present both in the peripheral and central nervous systems and are localized in several areas involved in mood regulation (e.g., hippocampus or prefrontal cortex). Moreover, they are involved in the regulation of neurotransmitter systems implicated in the pathophysiology of major depression (e.g., dopamine). Preclinical and clinical studies have suggested that $5-\mathrm{HT}_{3}$ receptors may be a relevant target in the treatment of affective disorders. $5-\mathrm{HT}_{3}$ receptor agonists seem to counteract the effects of antidepressants in non-clinical models, whereas 5$\mathrm{HT}_{3}$ receptor antagonists, such as ondansetron, have antidepressant-like activities. ${ }^{5}$ The involvement of 5$\mathrm{HT}_{3}$ receptors is complex and context-dependent. Their molecular structure, function, and regulation are only partly elucidated. Ondansetron is the most commonly prescribed antiemetic in chemotherapyinduced nausea and vomiting. ${ }^{6}$ These people are also at risk of developing depression. When these drugs are concomitantly prescribed in these patients, the efficacy of ondansetron is found to be decreased in these patients. ${ }^{7,8}$ The aim of this study is to understand the peripheral effects of fluoxetine and paroxetine on the intestinal motility of rabbits ileum in the presence of ondansetron.

\section{Materials and Methods}

\section{Animals and Housing Conditions}

Twenty four healthy local rabbits (Oryctolagus Cuniculus) both male and female (non-gravid) of 1-2 $\mathrm{Kg}$ weight were purchased from the local market. The animals were kept in animal house at Army Medical College, Rawalpindi, at room temperature. They went through $12 \mathrm{hrs}$ each of light and dark cycles and fed with a standard diet consisting of carrots, choker and grains along with tap water ad libitum.

\section{Chemical for Study}

Serotonin Carnitine Sulfate (Sigma Chemical Co.
USA), Ondansetron Hydrochloride (Werrick Pharmaceuticals Pak), fluoxetine (Werrick Pharmaceuticals Pak) and paroxetine (Werrick Pharmaceuticals Pak) were used. All the solutions and dilutions were prepared fresh in distilled water at the time of experiments. ${ }^{10}$

\section{Preparation of Tissue}

We culled an overnight fasting rabbit. The small intestine was taken out after identifying the cecum and was cut down into two-inch pieces. The intestinal tissue was cleaned by washing with normal saline and fatty tissues were dissected. The isolated tissue was then transferred to isolated organ bath of 50-milliliter capacity containing Tyrode's solution $\left(\mathrm{NaCl}, 136.8 \mathrm{mM} ; \mathrm{KCl}, 2.7 \mathrm{mM} ; \mathrm{MgCl}_{2}, 0.5 \mathrm{mM} ; \mathrm{CaCl}_{2}\right.$, $1.3 \mathrm{mM} ; \mathrm{NaH}_{2} \mathrm{PO}_{4}, 0.14 \mathrm{mM}$; $\mathrm{NaHCO}_{3}, 12.0 \mathrm{mM}$, Dextrose, $5.5 \mathrm{mM}$ ) and aerated continuously with $100 \%$ oxygen. The isotonic ileal smooth muscle activity was recorded through the displacement transducer DT-475 (USA). ${ }^{11}$ The system was connected to the iWorx/214(USA) and DIN connector was plugged on the cable of the DT-475 displacement transducer into channel 3 of the iWorx/214 unit. The tissue was allowed a period of equilibration of 15 minutes and the physiological solution was changed twice.

\section{Cumulative Dose-Response Curve Serotonin} Group 1 ( $n=6)$

The cumulative dose-response curve for serotonin was constructed by adding concentration of $10^{-9}$, $10^{-8}, 10^{-7}$ and $10^{-6} \mathrm{M}$ of serotonin. Each new concentration of serotonin was added after the achievement of maximal response from the preceding concentration. ${ }^{12}$

\section{Cumulative Dose-Response \\ Curve Ondansetron Group 2 ( $n=6$ )}

The cumulative dose-response curve for ondansetron was obtained by using concentrations of $10^{-9}, 10^{-8}, 10^{-7}$ and $10^{-6} \mathrm{M}^{13}$

\section{Fluoxetine Group 3 ( $n=6$ )}

The cumulative dose-response curve for fluoxetine was obtained using the concentration of $10^{-9}, 10^{-8}$, $10^{-7}$ and $10^{-6} \mathrm{M} \cdot{ }^{14}$ Fluoxetine effects were studied in the presence of a fixed concentration of ondansetron $10^{-6} \mathrm{M}(1 \mathrm{ml})$.

\section{Paroxetine Group $4(n=6)$}

The cumulative dose-response curve for paroxetine was obtained using the concentration of $10^{-9}, 10^{-8}$, 
$10^{-7}$ and $10^{-6} \mathrm{M}$ in a tissue pretreated with a fixed concentration of ondansetron $10^{-6} \mathrm{M}(1 \mathrm{ml}){ }^{15}$

\section{Statistical Analysis}

The results are expressed as means \pm standard error of means (SEM). The arithmetic means and SEMs. One-way analysis of variance (ANOVA) using SPSS version 20 ( Post hoc Tukey's) was applied for analyzing the three drugs. ${ }^{16}$

\section{Results}

Serotonin and ondansetron increases the contractility of intestinal smooth muscle. (Figure 1). Both exert a maximal increase in the contractile force of the ileal smooth muscle. However, paroxetine causes a significant depressive effect on intestinal motility (Figure 2) as compared to fluoxetine (Figure 3). This depressive response is responsible for the amelioration of ondansetron effects when used concomitantly with SSRIs in patients who suffer from SSRIs induced nausea and vomiting at the start of antidepressant therapy. The differences in response between fluoxetine and paroxetine in the presence of ondansetron (Group 3 and Group 4) are statistically significant (Table 1).

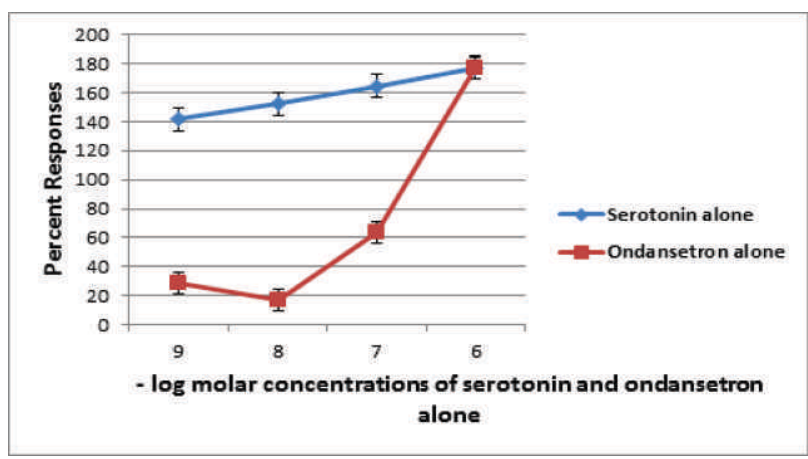

Fig 1: Semi log concentration-response curve of group 1 (serotonin) and group 2 (ondansetron) on isolated ileal smooth muscles of rabbit $(n=6)$. Data are represented as mean \pm standard error of means (SEM). The figure represents that both ondansetron and serotonin cause an increase in the ex-vivo smooth muscle contraction

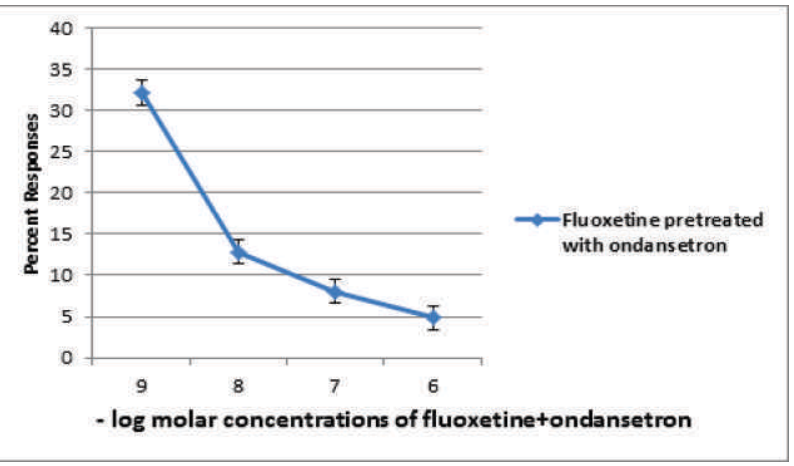

Fig 2: Semi log concentration-response curve of group 4 (Fluoxetine pre-treated with ondansetron) on isolated ileal smooth muscles of rabbit $(n=6)$. Data are represented as mean \pm standard error of means (SEM). The figure shows a marked decrease in the contractile response of fluoxetine in comparison to the control group

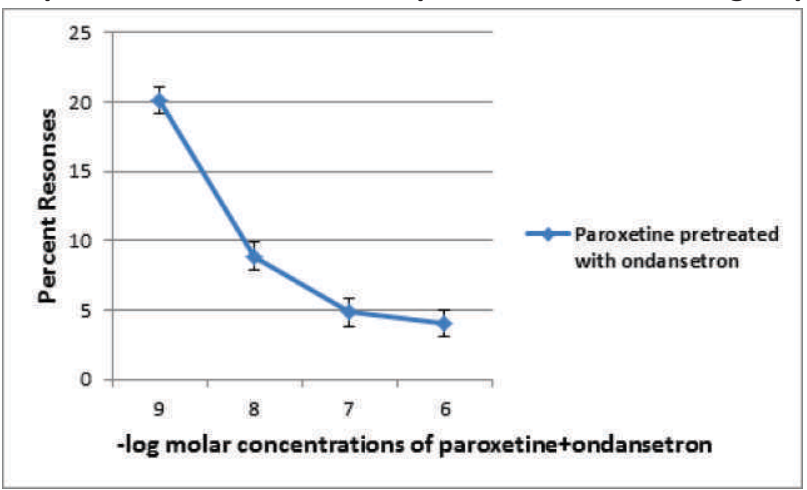

Fig 3: Semi log concentration-response curve of group 4 (Paroxetine pre-treated with ondansetron) on isolated ileal smooth muscles of rabbit $(n=6)$. Data are represented as mean \pm standard error of means (SEM). The figure shows a marked decrease in the contractile response of paroxetine in comparison to the control group

\begin{tabular}{|c|c|c|c|c|c|c|c|c|}
\hline Sr. No & Group 3 & Group 4 & Group 3 & Group 4 & Group 3 & Group 4 & Group 3 & Group 4 \\
\hline $\begin{array}{l}\text { Conc. of } \\
\text { Drugs M }\end{array}$ & . & $10^{-9}$ & $10^{-8}$ & $10^{-8}$ & $10^{-7}$ & $10^{-7}$ & $10^{-6}$ & $10^{-6}$ \\
\hline 1 & $15(\mathrm{~mm})$ & $5(\mathrm{~mm})$ & $5(\mathrm{~mm})$ & $3(\mathrm{~mm})$ & $2(\mathrm{~mm})$ & $3(\mathrm{~mm})$ & $2(\mathrm{~mm})$ & $2(\mathrm{~mm})$ \\
\hline 2 & 8 & 6 & 4 & 2 & 3 & 1 & 2 & 1 \\
\hline 3 & 10 & 5 & 3 & 3 & 1 & 1 & 1 & 1 \\
\hline 4 & 6 & 6 & 4 & 3 & 3 & 2 & 1 & 1 \\
\hline 5 & 10 & 4 & 3 & 2 & 2 & 1 & 1 & 1 \\
\hline 6 & 6 & 4 & 2 & 1 & 1 & 1 & 1 & 1 \\
\hline Mean & 8 & 5 & 3.2 & 2.2 & 2 & 1.2 & 1.2 & 1 \\
\hline SD & 3.371 & 0.894 & 1.0488 & 0.816 & 0.894 & 0.836 & 0.516 & 0.408 \\
\hline SEM & 1.12 & 0.298 & 0.349 & 0.272 & 0.298 & 0.278 & 0.172 & 0.136 \\
\hline Pvalue & \multicolumn{2}{|c|}{$0.001^{*}$} & \multicolumn{2}{|l|}{0.3} & \multicolumn{2}{|c|}{$0.002^{*}$} & \multicolumn{2}{|c|}{$0.025^{*}$} \\
\hline
\end{tabular}

$P$ value $>0.05=$ Not Significant $(\mathrm{Ns})$

$P$ value $<0.05=$ Significant $(*)$

\section{Discussion}

The study was designed to evaluate the contractile effects of commonly used selective serotonin reuptake inhibitors (fluoxetine and paroxetine) on gastrointestinal smooth muscles of rabbit in vitro and to observe the modulatory role of ondansetron on the contractility of the smooth muscles of the rabbit.

That serotonin has diverse motor and sensory functions in the gastrointestinal tract through submucosal and myenteric neurons. ${ }^{17}$ Serotonin influences the gastrointestinal motility by acting 
directly through $5-\mathrm{HT}_{4}$ receptors on enterocytes and indirectly via $5-\mathrm{HT}_{3}$ receptors on mucosal nerves and vagal afferents. ${ }^{18}$ Studies have shown an increase in contractile response of serotonin as compared to the response produced by acetylcholine. ${ }^{15} 5-\mathrm{HT}_{4}$ receptors are G-protein-coupled receptors and are located on both cholinergic interneurons and motor neurons. ${ }^{16}$ The stimulation of $5-\mathrm{HT}_{4}$ receptors causes an increase in the acetylcholine release which in turn increases the colonic motor activity. ${ }^{19}$

Almost $90 \%$ of serotonin is stored in the enterochromaffin cells. Serotonin modulates the intestinal fluid, electrolyte secretion and intestinal motility. ${ }^{20}$ Serotonin mediated contractions was taken as a control for the study and its response was taken as $100 \%$.

Ondansetron is a serotonin-3 (5-hydroxytryptamine3, 5-HT3) receptor antagonist. Its antiemetic effects are decreased when used concomitantly with SSRIs. Ondansetron is one of the best known 5-HT3 receptor antagonists, blocking receptors at vagal and sympathetic nerves and the chemoreceptor triggering zone. ${ }^{14,15}$ However, 5-HT3 receptor antagonists not only inhibit transmission of signals to the CNS, but they also decrease intestinal motility, presumably by interfering with serotonergic neurotransmission within the enteric nervous system (ENS) and blocking the initiation of reflexes. Ondansetron effects act both at peripheral and central nerves. It reduce the activity of the vagus nerve, which is a nerve that activates the vomiting center in the medulla oblongata; and also block serotonin receptors in the chemoreceptor trigger zone. All these factors contribute to an increase in intestinal activity leading to diarrhea in some patients and alternatively constipation in other patients. ${ }^{21}$

Janssen observes the same decrease in amplitude of contraction by SSRI's, postulating that SSRI's do not have an intrinsic activity but have an affinity for $5-\mathrm{HT}_{3}$ receptors. ${ }^{18} \mathrm{The} 5-\mathrm{HT}_{3}$ and $5-\mathrm{HT}_{4}$ receptors on cholinergic nerves along with $5-\mathrm{HT}_{2 \mathrm{~A}}$ receptors on smooth muscles, mediate relaxation via release of nitrous oxide (NO) and adenosine triphosphate (ATP) as end neurotransmitters. Prolonged use of SSRIs cause sensitivity of $5-\mathrm{HT}_{1 \mathrm{~A}}$ and $5-\mathrm{HT}_{2}$ receptors leading to decrease in contractile response in the presence of antagonists. ${ }^{22}$

\section{Conclusion}

The study concluded that ondansetron has peripheral and central actions, which contribute to its actions in chemotherapy-induced nausea and vomiting. Concomitant use of ondansetron with SSRIs reduces their antiemetic and antidepressant effects as both antagonize their effect by acting on the peripheral serotonergic receptors. Further exploratory work is required to observe the chronic effects of ondansetron and SSRI's on intestinal motility and CTZ. The muscarinic agonists and antagonists should be used to further understand the mechanism of action.

\section{Acknowledgment}

We are thankful to NUST (National University of Science \& Technology Islamabad) for funding the research.

\section{REFERENCES}

1. Cecille B, Adeline E, Chris O, Bjarka E, Connie S, Nasser H. Role of 5-HT3 receptors in the Antidepressant Response. Pharmaceuticals. 2011; 4:603-29.

2. Richards R. Is chemotherapy always necessary for breast cancers? Ehow Health (newsletter) National Cancer Institute, National Institutes of Health. 2013.

3 Afzal A, Khan BT, Bakhtiar S. Ondansetron: A newer aspect of the dose-response relationship on ileal smooth muscles of rabbit Pak. J. Pharm. Sci. 2016; pp: 119-24.

4. Afzal A, Ajmal K, Sabeen S. Paroxetine: An update of response on intestinal motility J Pak Med Assoc. 2016; 66: 240-2.

5. Cohen IT. An overview of the clinical use of ondansetron in preschool-age children. Ther Clin Risk Manag. 2007; 3: 3339.

6. Devita VT, Rosenberg SA. Two Hundred Years of Cancer Research. N. Engl. J. Med. 2012; 366: 2207-14.

7. Rogers MP, Blackburn L. Use of neurokinin-1 receptor antagonists in patients receiving moderately or highly emetogenic chemotherapy. Clinical. J. ONS. 2010; 14: 500-4.

8. Spiller R. Serotonergic modulating drugs for functional gastrointestinal diseases. Br. J. Pharmacol. 2002; 54: 11-20.

9. Jabeen $Q$, Aziz N, Afzal Z, Gilani HA. The spasmogenic and spasmolytic activities of Lavandula Stoechas are mediated through muscarinic receptor stimulation and calcium channel blockade. Int. J. Pharmacol. 2007; 3: 61-7.

10. Noor A, Najmi MH, Bakhtiar S. Effect of bradykinin-induced contraction on isolated smooth muscle of guniea pig . Indian Journal of Pharmacology. 2011; 43: 449-55.

11. Bajetta E, Puscedd S, Guadalupi V, Ducceschi M, Celio L. Prevention of acute chemotherapy-induced nausea and vomiting. The role of palonosetron. Cancer Manag Reo. 2009; 1: 89-97.

12. Barrack S. Selective serotonin reuptake inhibitors (SSRIs). J. 
Neurology Version. 2016; 29: 954-6.

13. Basch $E$, Abernethy AB. Supporting clinical practice decisions with the real-time-patient-reported outcome. J Clin Oncol. 2011; 29: 954-6.

14. Chetty N, Irving RH, Coupar MI. Activation of 5-HT3 receptors in the rat and mouse intestinal tract: $A$ comparative study. Br. J. Pharmacol. 2006; 148: 1012-21.

15. Gregory VC, Lucki I. The role of serotonin receptor subtypes in treating depression: A review of animal studies. Psychology. 2010; 213: 265-87.

16. Hajdu SI, Thun MJ, Hannan LM, Jemal A. A note from history: Landmark in history of cancer. Cancer 2011; 117: 1097-102.

17. Hawkin's R, Gunberg S. Chemotherapy-induced nausea and vomiting. Challenges and opportunities for improved patient outcomes. Clin. J. Oncol. Nurs. 2009; 13: 54-64.

18. Janssen P, Oudenhove VL, Castcels C, Vos R, Verbeke K, Tack J. The effect of acute citalopram dosing on gastric motor function and nutrient tolerance in healthy volunteers. Aliment Ther. 2010; 33: 395-402.

19. Mujezinovic I, Cupic V, Samajlovic A, Muminovic M. Identification of serotonergic $\left(5-\mathrm{H}_{1 A}\right.$-Type) receptor in broiler small intestine by application of its serotonin and antagonist. Vetnary glasnick. 2011; 65: 51-9.

20. Mir O, Durand JP, Boudou-Rouquette P, Giroux J, Coriat R, Cessot $A$, et al. Interaction between serotonin reuptake inhibitors, 5-HT3 antagonists, and NK1 antagonists in cancer patients receiving highly emetogenic chemotherapy: a case-control study. 2012; 20:2235-9.

21. Mujezinovic I, Cupic V, Samajlovic A, Muminovic M. Identification of serotonergic (5-H1A-Type) receptor in broiler small intestine by application of its serotonin and antagonist. Vet. glasnick. 2011; 65:51-9.

22. Pithadia BA, Jain MS. 5-Hydroxytryptamine receptor subtypes and their modulation with therapeutic Potentials. J. of Clin. Med Res. 2009; 1: 72-80. 